\title{
Therapeutic Potential of TRPM Modulator
}

\author{
Nitin Rawat, Hemprabha Tainguriya and Anil Kumar* \\ Pharmacology Department, University Institute of Pharmaceutical Sciences, UGC Centre of Advanced Studies (UGC-CAS), Panjab University, \\ India \\ *Corresponding author: Anil Kumar, Professor of Pharmacology, Former Dean, Faculty of Pharmaceutical Sciences, University \\ Institute of Pharmaceutical Sciences, UGC Centre of Advanced Studies (UGC-CAS), Panjab University, Chandigarh, India
}

\begin{abstract}
Transient Receptor Potential of the family Melastatin (TRPM) is a group of nonselective cation channel, engaged in various daily activities of the body. The family's first member (TRPM1) was cloned in 1998 capable of supressing the tumour in melanocytes of skin. Soon after TRPM1 was discovered, another family member was discovered, that includes TRPM2 (channel sensitive to oxidative stress present in microglial cells), TRPM3 (channel activating renal homeostasis that is activated by sphingosine), TRPM4/5 (Ca ${ }^{+2}$ activated sister channel involved in conduction of monovalent cation), TRPM6/7 (chanzymes related to Mg ${ }^{+2}$ homeostasis), TRPM8 (thermosensitive $\mathrm{Ca}^{+2}$ permeable channel). This review will summarize activation of key structural features mechanism and therapeutic potential of drug modulating TRPM channels.
\end{abstract}

Keywords: Transient Receptor Potential (TRP) Channels; TRPM Modulators; Neurodegenerative Diseases; Cancer

\section{Introduction}

Transient Receptor Potential (TRP) channels are group of membrane proteins that play a key role in managing variety of physiological function ranging from controlling of second messenger $\left(\mathrm{Ca}^{+2}\right)$ availability and nerve conduction to sensing extracellular $\mathrm{pH}$, osmolar balance of and environmental temperature(TRPV1-4, TRPA1, and TRPM8) [1]. First TRP was brought into light after Cosens and Manning work in 1969, on photo transduction in mutant species of fruit fly (Drosophila melanogaster) that exhibited blindness under intense bright light, because it induces mutation in the trp gene of Drosophila, during the cloning of trp gene first member of drosophila came into existence (Baruch Minke, 2010). Mammalian TRP subfamily contains 28 cation permeable channels that are grouped according to amino acid sequence homology into six subfamilies. Canonical TRPs (TRPCs), Vanilloid TRPs (TRPVs), Melastatin TRPs (TRPMs), Mucolipins (TRPMLs), Polycystins (TRPPs), Ankyrin transmembrane protein 1 (TRPA1) [2]. These subfamilies of TRPs are further classified based on their localization and activation/inhibition by different endogenous and exogenous modulator. TRPM subfamily is one of the indispensable group of ion-channel that is ubiquitously expressed and intricately involved in pathophysiology of various neurological disorder. In this review, we focus on the complicity TRPM in various diseases (Alzheimer's, Parkinson's cerebral ischemia neuropathic pain etc.) and underlying mechanism of its modulation for the treatment of these diseases (Figure 1). 


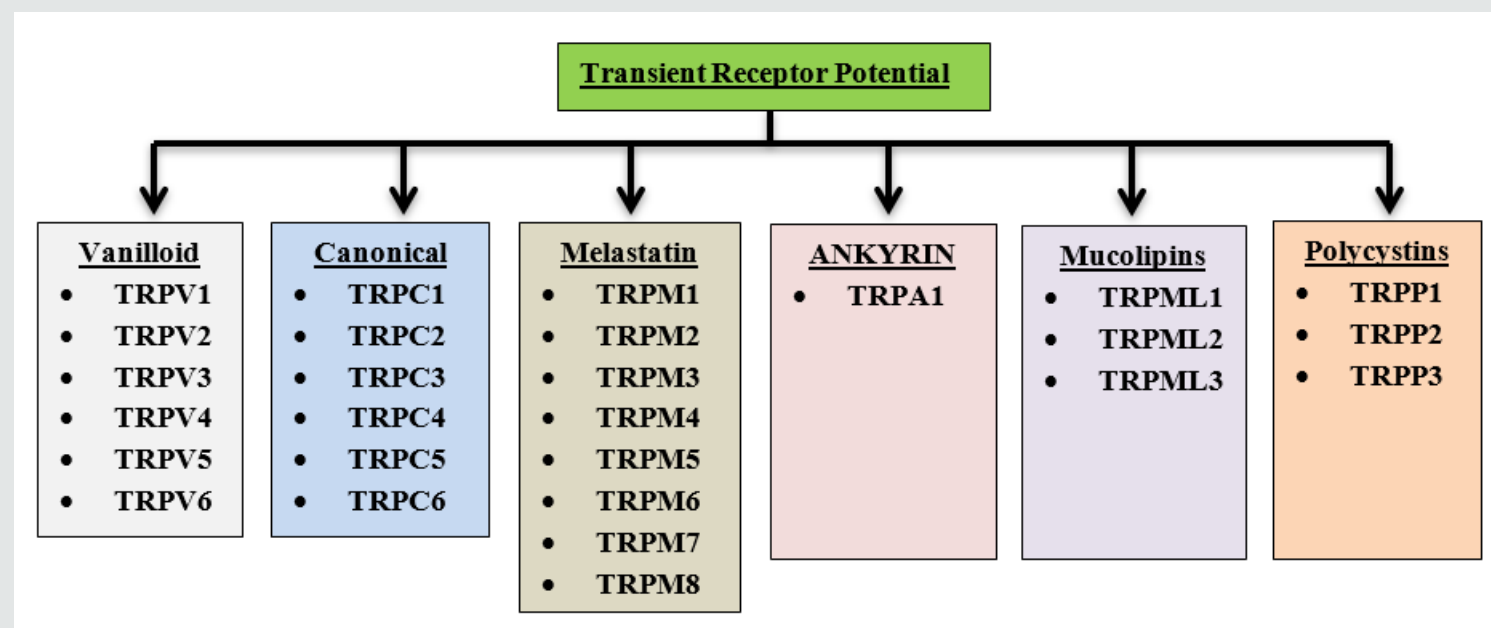

Figure 1: Subfamilies of TRP.

\section{TRPM Channel and its Structural Features}

TRPM subfamily of ion channels has eight members, subdivided into four classes on the basis of their structural similarity: TRPM1/3, TRPM6/7, TRPM4/5, and TRPM2/8. TRPM protein consists of six transmembrane units, a pore between 5 and 6 units and two intracellular regulatory domains ( $C$ and $\mathrm{N}$-terminal). C-terminal comprised of 1000-2000 AA that include TRP box sequence and coiled-coil domain responsible for channel tetramerization. The N-terminal consisting of 300-400 AA, has various binding sites in different channel. The TRPM family has varying degree of permeability of $\mathrm{Ca}^{+2}$ and $\mathrm{Mg}^{+2}$ permeability from impermeable (TRPM4/5) to extremely permeable (TRPM6/7), three members(TRPM2/6/7) are chanzymes (includes enzyme in intracellular C-domain, TRPM2 has nudix hydrolases (NUDT9-H) and TRPM6/7 have kinase proteins) [1].

TRPM1/3 are cation channels that are non-selective calcium permeable. In human, TRPM subfamily member i.e. TRPM1 which is cloned from benign melanomasgeneis based on face, skin, eye and pigment cell chromosome 15 , which contains $5.4 \mathrm{~kb}$ mRNA transcript, encodes to 1603AA. TRPM3's C-terminal includes TRP box whereas $\mathrm{N}$-terminal contains two Calmodulin binding sites. Like TRPM1, TRPM3 has 6 mRNA transcript forms cloned from human kidney. TRPM3 is found in human's brain and kidney and is involved in renal osmo-homeostasis. TRPM3 is triggered by steroids like pregnenolone sulphate, that reveals its steroidal essence [3].

TRPM4/5 are monovalent non- selective cation channels that are activated by $\mathrm{Ca}^{2+}$. They have similarity (about $50 \%$ identical) in their sequence homology and share common properties such as channel regulation, ion selectivity, voltage-dependency. TRPM4 $\mathrm{N}$-terminal contains a nucleotide binding domain (NBD) with ATP binding and channel inhibiting operations [4]. TRPM6/7 is a bi functional protein capable of penetrating ion $\left(\mathrm{Mg}^{2+}, \mathrm{Zn}^{2+}\right.$ and $\left.\mathrm{Ca}^{2+}\right)$ . At their C- terminal kinase protein domain that helps them to act as chanzyme. TRPM7 ubiquitously expressed, primarily involved in the conduction of $\mathrm{Mg}^{2+}$ and $\mathrm{Zn}^{2+}$. It is needed for the embryonic mouse development [5].

Unlike TRPM6/7, TRPM2 is also a bi-functional cation channel which is permeable to $\mathrm{Ca}^{2+}, \mathrm{Na}^{+}$and $\mathrm{K}^{+}$. C-terminal of TRPM2 is mapped with enzyme nudix hydrolases (NUDT9-H) which binds to ADPR and activates TRPM2. High Intracellular $\mathrm{Ca}^{2+}$ concentration can activate the TRPM independently or in combination with ADPR by binding to the $\mathrm{N}$ - terminus with a calmodulin-binding motif [6]. TRPM8 is a nonselective, temperature sensitive $\mathrm{Ca}^{+2}$ permeable cation channel, situated in dorsal root ganglion (DRG) of sensory neurons and trigeminal neurons. It is predominantly cloned from prostate cancer cell. Phosphoinositide binds with C- terminal and TRP box sequences, modulates the activity of TRPM8. Coiled coil C-terminal domain is responsible for channel assembly, trafficking, and activation by temperature [7] (Figure 2) (Table 1). 


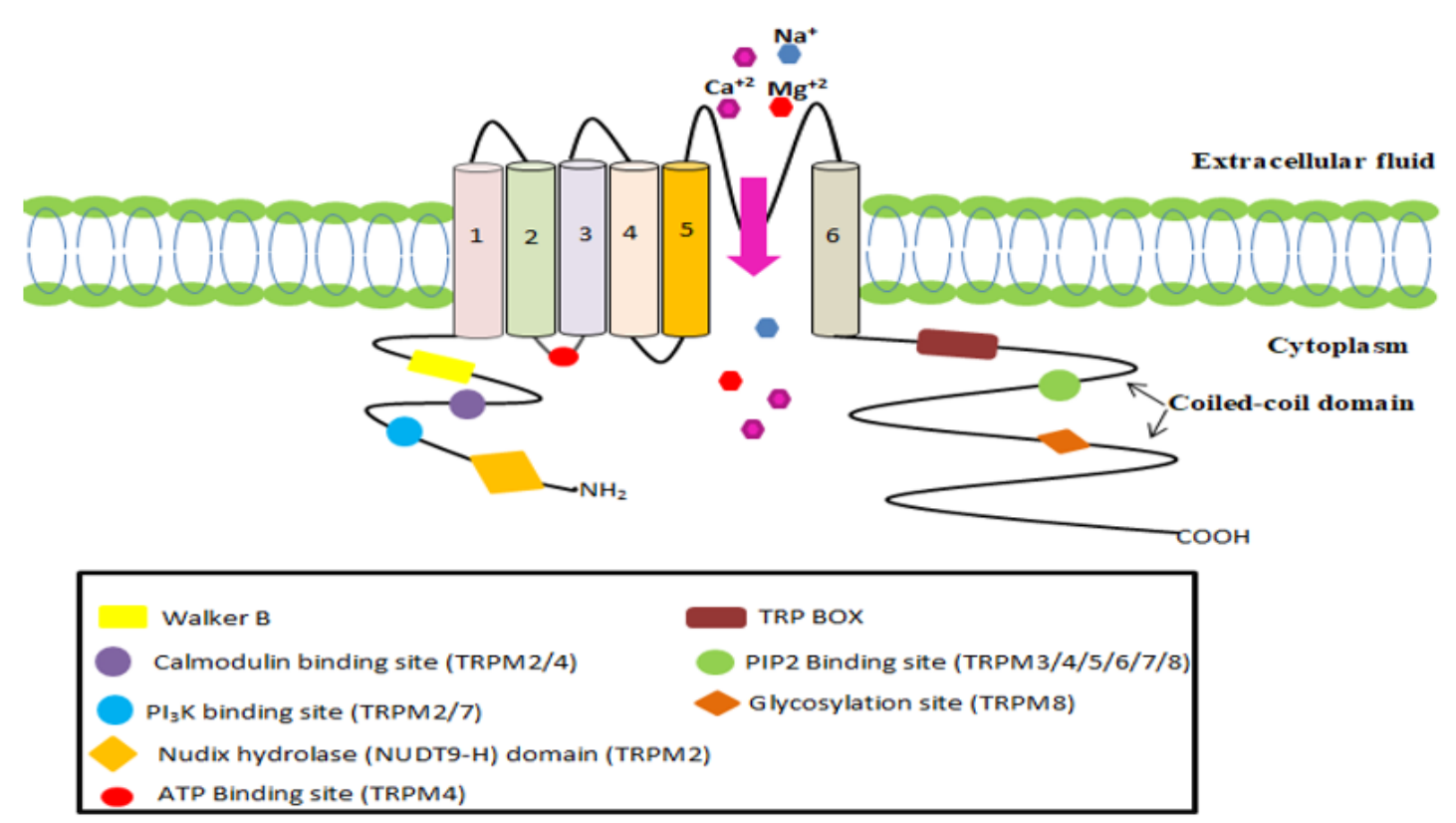

Figure 2.

Table 1: Functional role of TRPM modulators.

\begin{tabular}{|c|c|c|c|}
\hline TRPMs and their location & Physiological Function & Disease & Modulators \\
\hline $\begin{array}{l}\text { TRPM1 } \\
\text { Brain, melanocytes, eye, skin }\end{array}$ & $\begin{array}{l}\text { bipolar cell depolarisation; prognostic } \\
\text { marker of tumour suppression for } \\
\text { melanoma metastasis. }\end{array}$ & $\begin{array}{l}\text { Stationary congenital } \\
\text { nocturnal blindness. }\end{array}$ & $\begin{array}{l}\text { Stimulators: Pregnenolone sulphate } \\
\text { Inhibitors: } \mathrm{Zn}^{2+}\end{array}$ \\
\hline $\begin{array}{c}\text { TRPM2 } \\
\text { Macrophages, brain, } \\
\text { pancreatic } \beta \text { cells, bone } \\
\text { marrow }\end{array}$ & $\begin{array}{l}\text { Sensation of core body temperature; } \\
\text { Oxidative sensation; Insulin secretion; } \\
\text { Immune reaction. }\end{array}$ & $\begin{array}{l}\text { Bipolar disorder, Cerebral } \\
\text { ischaemia, Alzheimer`s } \\
\text { disease, Neuropathic pain }\end{array}$ & $\begin{array}{c}\text { Stimulators: ADPR, cADPR, 2'-deoxy-ADPR, } \\
\text { 2-P-ADPR, 3-P-ADPR, } 2 \text { F-ADPR, AMPCPR, } \\
\qquad \text { Ca }^{2+} \\
\text { Inhibitors: Clotrimazole, econazole } \\
\text { flufenamic acid, N-(p- amylcinnamoyl) } \\
\text { anthranilic acid, 2-APB, scalardial, 3-MFA, } \\
\text { 8-Br-cADPR, 8-Br-ADPR, 8-Ph- ADPR, 8-Ph- } \\
\text { 2-deoxy-ADPR, 8-(3-acetylphenyl)-ADPR, } \\
\text { 8-thiophenyl-ADPR, and More }\end{array}$ \\
\hline $\begin{array}{c}\text { TRPM3 } \\
\text { Dorsal root ganglia, Kidney } \\
\text { cardiomyocytes, pancreatic } \\
\text { beta-cells, Nociceptive } \\
\text { Primary neurons }\end{array}$ & $\begin{array}{l}\text { Neurotransmitter release regulator, iris } \\
\text { constriction, renal osmo-homeostasis, } \\
\text { Glucose homeostasis, sensitive to } \\
\text { temperature and inflammatory pain. }\end{array}$ & $\begin{array}{l}\text { Cataract, glaucoma, Visual } \\
\text { epilepsy; Retinal disorder. }\end{array}$ & $\begin{array}{l}\text { Stimulators: Sphingolipids, pregnenolone } \\
\text { sulfate (PS), and nifedipine, CIM0216 } \\
\text { extracellular osmolarity, swelling, heat } \\
\left(40^{\circ} \mathrm{C}\right) . \\
\text { Inhibitors: primidone }\end{array}$ \\
\hline $\begin{array}{c}\text { TRPM4 } \\
\text { Pancreas, heart, prostate, } \\
\text { renal tubule, and liver }\end{array}$ & $\begin{array}{l}\mathrm{Ca}^{+2} \text { dependent Dendritic cell activation } \\
\text { and T-lymphocyte Secretion of Insulin } \\
\text { Prevention of heart conduction disorders } \\
\text { Regulation of smooth muscle contraction. }\end{array}$ & $\begin{array}{c}\text { Brugada syndrome; } \\
\text { Cardiac conduction fault. }\end{array}$ & $\begin{array}{c}\text { Stimulators: } \mathrm{Ca}^{2+} \\
\text { Inhibitors: ATP, ADP, AMP, 9-phenanthrol. }\end{array}$ \\
\hline $\begin{array}{c}\text { TRPM5 } \\
\text { Taste bud, beta-cells } \\
\text { of pancreas; Tuft cells; } \\
\text { Chemosensory Solitary cells. }\end{array}$ & $\begin{array}{c}\text { Modulation of insulin secretion and } \\
\text { sensory transduction in taste } \\
\text { cells. }\end{array}$ & $\begin{array}{l}\text { Beckwith-Wiedemann } \\
\text { syndrome }\end{array}$ & $\begin{array}{c}\text { Stimulators: } \mathrm{Ca}^{2+}, \mathrm{PIP}^{2} \text {, steviol glycosides, } \\
\text { rutamarin. } \\
\text { Inhibitors: TPPO } \\
\text { (Triphenylphosphorus oxide) }\end{array}$ \\
\hline $\begin{array}{l}\text { TRPM6 } \\
\text { Intestine, brain, pituitary, } \\
\text { and distal convoluted tubule } \\
\text { (DCT) of the kidney }\end{array}$ & $\begin{array}{l}\text { Renal Magnesium homeostasis and } \\
\text { intestine. } \\
\text { Has an atypical kinase domain, letting } \\
\text { them to work as “Chanzymes," capable of } \\
\text { phosphorylating and Channel activation. }\end{array}$ & $\begin{array}{l}\text { Secondary hypocalcaemia } \\
\text { (HSH) autosomal recessive } \\
\text { hypomagnesemia }\end{array}$ & $\begin{array}{l}\text { Stimulators: } \mathrm{Mg}^{2+} \\
\text { Inhibitors: ruthenium red }\end{array}$ \\
\hline
\end{tabular}




\begin{tabular}{|c|c|c|c|}
\hline $\begin{array}{l}\text { TRPM7 } \\
\text { Ubiquitously present }\end{array}$ & $\begin{array}{c}\mathrm{Mg}^{2+}-\text { and } \mathrm{Ca}^{2+} \text {-permeable cation channel } \\
\text { with activity on protein kinase. } \\
\text { Has an atypical kinase domain, letting } \\
\text { them to work as "chanzymes," capable } \\
\text { of phosphorylating and activating the } \\
\text { channel. }\end{array}$ & $\begin{array}{c}\text { Neurodegenerative } \\
\text { disorders }\end{array}$ & $\begin{array}{l}\text { Stimulators: } \mathrm{Mg}^{2+}-\mathrm{ATP} \text {, breakdown of PIP2, } \\
\text { rise in cAMP concentrations } \\
\text { Inhibitors: } \mathrm{Mg}^{2+} \text {, spermine, 2-APB(2- } \\
\text { Aminoethyl diphenylborinate), } \\
\text { MnTBAP(manganese (III) tetrakis } \\
\text { (4-benzoic acid) porphyrin) }\end{array}$ \\
\hline $\begin{array}{c}\text { TRPM8 } \\
\text { Cancer cells in the prostate, } \\
\text { dorsal root ganglion (DRG) } \\
\text { sensory neurons and } \\
\text { trigeminal neurons }\end{array}$ & $\begin{array}{c}\text { Nonselective, } \mathrm{Ca}^{2+} \text {-permeable cation } \\
\text { channel. Thermoregulation, nociception, } \\
\text { urinary bladder function. }\end{array}$ & $\begin{array}{l}\text { Inflammatory/neuropathic } \\
\text { pain; Prostate cancer, } \\
\text { adenocarcinoma, breast } \\
\text { cancer }\end{array}$ & $\begin{array}{l}\text { Stimulators: cool temperature }\left(<28^{\circ} \mathrm{C}\right) \\
\text { and cooling agents like menthol, eucalyptol } \\
\text { andicilin } \\
\text { Inhibitors: WS-12, CPS-369. }\end{array}$ \\
\hline
\end{tabular}

\section{Physiological and Pathophysiological Role of TRPM Channels in Various Diseases}

\section{Neurodegenerative diseases}

Alzheimer's disease: Study of cultured rat striatal neurons showed that the concentration of $\mathrm{H}_{2} \mathrm{O}_{2} / \mathrm{A}_{42}$ was dependent neurodegeneration by TRPM2 channel overexpression which is further confirmed by increased $\mathrm{Ca}^{+2}$ levels in the neurons and suppression of neurodegeneration by TRPM2 antagonist (2-aminoethoxydiphenyl borate (2-APB) or N-[(p-amylcinnamoyl) anthranilic acid (ACA)]. These results evidenced the consistent involvement of TRPM2 in ROS/A $\beta_{42}$-induced neuronal death [8]. In normal individuals, TRPM7 aids in synaptic plasticity, learning, memory and cognition. Unlike TRPM2, it is also activated by oxidative stress which contributes to increased intracellular $\mathrm{Ca}^{+2}$ and activates many enzymes which are dependent on $\mathrm{Ca}^{+2}$ including calpain and the endonuclease pathways which ultimately cause changes in the cytoskeleton and cell death. Presenilin (PS) gene mutations which are common cause of Familial AD, also cause imbalance in $\mathrm{PIP}_{2}$ (modulator of TRPM7) metabolism. The $\mathrm{PIP}_{2}$ deficiency is also correlated with $A \beta_{42}$ level because $A \beta$ increases the level of $\mathrm{PIP}_{2}$ by inhibiting PLC mediated conversion to $\mathrm{IP}_{3}$ and DAG in cholinergic neuron. According to a study TRPM7 induced $\mathrm{Ca}^{+2}$ deficiency in the presenilin mutated cells and is restored by the addition of PIP $_{2}$. This study suggested that TRPM7 can influence the normal functioning of presenilin [9] (Figure 3).

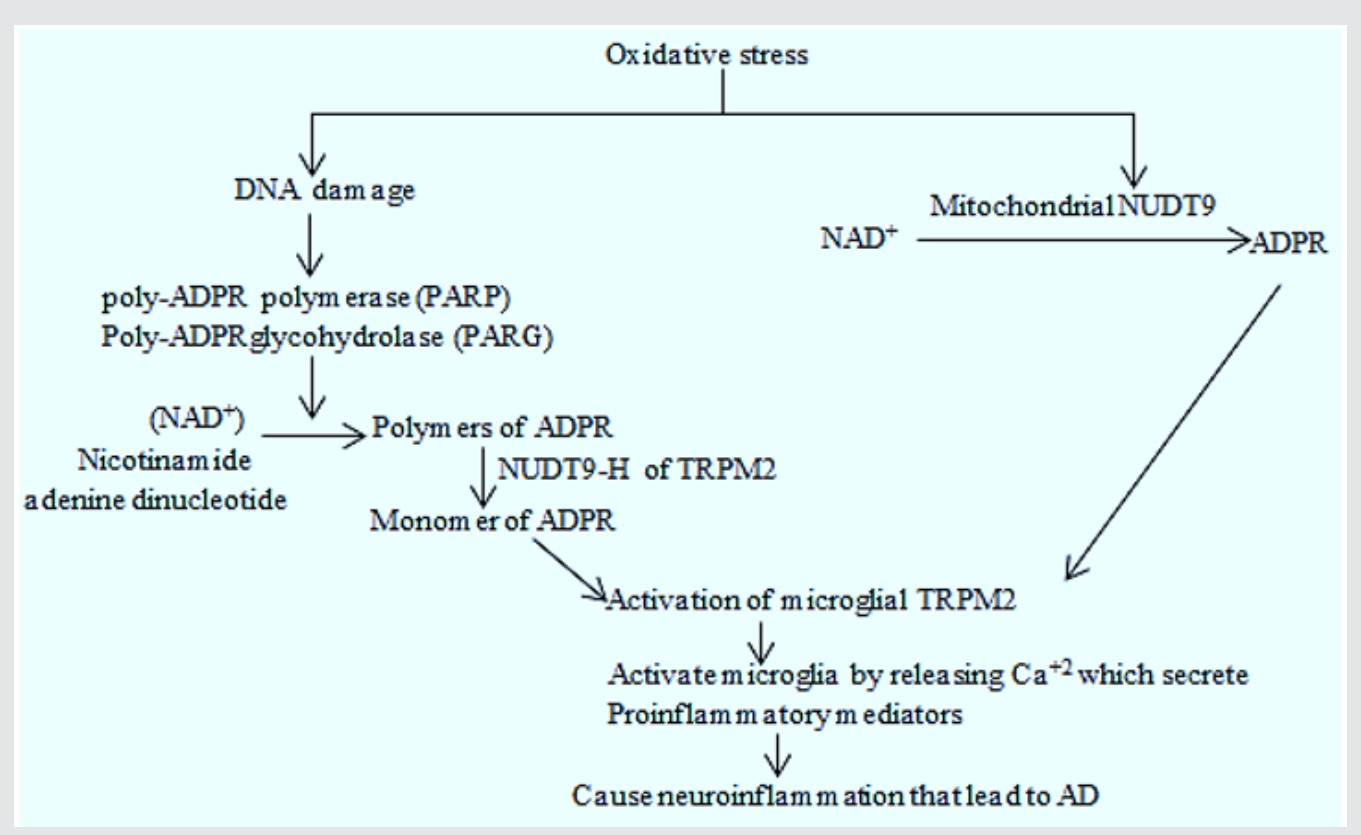

Figure 3.

Ischemic stroke: As previously mentioned oxidative stress is the key factor that stimulate TRPM2/7 is closely related with ischemia. However, number of studies demonstrated the role of $\mathrm{Ca}^{+2}$ permeable cation channel such as pannexin channel, TRPM7 and TRPM2 in oxidative stress associated ischemia. In studies on transient middle cerebral artery occlusion (tMCAO) rat model of ischemia and cultured neuron under hypoxic condition demonstrated the tremendous increase in TRPM2/7 in brain microglial cells. That creates $\mathrm{Ca}^{+2}$ overload which ultimately lead to neuronal cell death. Pharmacological blocker and sh-RNA targeting TRPM2/7 can attenuated $\mathrm{Ca}^{+2}$ overload induced neuronal cell death [9] (Malko et al., 2019). 
Parkinson's disease: Parkinson's is a neurodegenerative disorder characterized by the selective loss of the dopaminergic neurons in the substantia nigra pars compacta. It is also clinically shown that patients with $\mathrm{PD}$ shows a remarkable increase of Reactive Oxygen Species (ROS) in specific brain regions. Over production of ROS \& oxidative stress is involved in PD leading to neuronal death \& apoptosis. Inhibition of ROS production could be the criteria to halt the progression of PD. It is now well established that mitochondrial inhibitors such as 6-hydroxydopamine (6OHDA) can induce neuronal loss in PD. miRNA's (microRNA's) could regulate post transcriptional gene expression and neuronal disease. RT-PCR showed that miRNA-22 is downregulated in 6-OHDA induced PC12 cells, this mediates ROS production \& Upregulation of caspase-3 activity. TRPM7 is a direct target gene for miR-22 and its overexpression markedly downregulate the level of TRPM7. Many evidences have shown that TRPM7 can cause dysregulation of miRNA which is involved in the early pathogenesis of PD. TRPM7 can mediate excitotoxic -dependent neuronal death. ROS activated TRPM7 induced toxic $\mathrm{Ca}^{+2}$ influx into neurons during oxygen glucose deprivation (OGD) treatment and it can cause death of neurons when activated in hypoxic-cultured neurons. TRPM7 overexpression blocks the effect of miRNA-22 overexpression on 6-OHDA induced PC12 cell survival and proliferation. ROS production which was downregulated by miRNA overexpression is also delayed by TRPM7 overexpression. Many findings suggested that miRNA overexpression suppresses TRPM7 expression the resulting low level of TRPM7 promotes 6-OHDA induced PC12 cell survival in the PD diagnosis and treatment [10].

TRPM2 mediates the cell death in non-neuronal cells by increasing susceptibility to ROS including $\mathrm{H}_{2} \mathrm{O}_{2}, \mathrm{TNF} \alpha$, Amyloid $\beta$ peptide. Reduction of these channel can increase cellular resistance to damage. Functional expression of TRPM2 is involved in dopaminergic SNc neurons by promoting oxidative stress as these channels are sensitive to oxidative stress. $\mathrm{MPP}^{+}$is a potential neurotoxin which selectively destroys the dominergic neurons in humans and cause PD like symptoms. This causes oxidative stress which activates TRPM2 leading to the $\mathrm{Ca}^{+2}$ entry, this increases calpain activation and this further causes apoptosis. TRPM2 knockdown prevented $\mathrm{MPP}^{+}$induced cellular death by inhibiting apoptosis in neuronal cells whereas it's overexpression increases cell loss. Hence inhibition of TRPM2 could be an effective mean to protect cells against degeneration caused by neurotoxin $\mathrm{MPP}^{+}[11]$.

\section{Cancer}

Prostate cancer: In healthy tissues, TRPM4 is important for cell migration. It regulates T- Lymphocytes and mast cell expression. In inflammatory condition TRPM4 is involved in vascular endothelial cell migration with the production of reactive oxygen species. So TRPM4 was proven to mediate intracellular calcium levels in these cells. Now in cancerous cells, TRPM4 is associated with migration, proliferation and invasion of these cells. It causes silencing of shRNA which promotes degradation of beta catenin and inhibit transcription. This results in suppression of cell proliferation. In prostate cancer, knockdown of TRPM4 by siRNA could reduce cell migration but not proliferation of the androgen insensitive prostate cancer cell lines. TRPM4 was shown to be regulated by microRNA-150 in prostate cancer which targets the TRPM4 gene directly and thus suppresses TRPM4 Expression. As a nonselective monovalent cation channel ,TRPM4 upregulation and activation enhances $\mathrm{Na}$ entry which leads to the depolarization of the membrane potential, which is involved in regulating calcium influx , so the disturbed calcium homeostasis is always associated with the behavior of cancerous cells [12].

TRPM8 also plays an important role in physiology of prostate cancer as it localizes to the ER and plasma membrane and has been reported to form $\mathrm{Ca}^{+2}$ permeable channels at both the locations. TRPM8 expression is enhanced by androgens. It regulates $\mathrm{Ca}^{+2}$ homeostasis in prostate in prostate epithelial cells $\&$ is required for cell survival defining a potential target for management of prostate cancer [13].

TRPM2 network specializes in the proliferation of prostate cancer cell. mRNA level in prostate cancer tissue is higher. The expression of TRPM2 transcript is found to be greater in malignant epithelial cells than in benign cells. Unlike healthy cell lines, in which TRPM2 is found in plasma membrane and cytosol (lysosome). PC3 cells show where they are located in nuclei too. TRPM7 is involved in PCa cells compared to prostate hyperplasia cells, which triggers its migration to these cells. TRPM7 deficiency by a knockdown in PCa cells suppressed migration and invasion of distinct PCa cell lines.

Pancreatic cancer: TRPM7 is mainly involved in this cancer. It is 13 fold expressed in cancer tissues as compared to healthy ones. It's expression correlates with the PDAC Progression which is inversely related to the patient survival. TRPM7 modulates BXPC3 cell migration which is $\mathrm{Mg}^{+2}$ dependent. TRPM7 increases PDAC cell invasion through the regulation of the proteolytic axis, MMP2 pathway. This axis is significantly decreased in TRPM7-deficient PDAC cells. TRPM2 is negatively correlated with patient survival rate, the more TRPM2 is expressed in cancerous tissue, the shorter the survival times displayed by PDAC patients. Its overexpression is associated with the increased cell proliferation and invasive ability. TRPM8 expression is markedly upregulated in human pancreatic adenocarcinoma cell lines\& tissues which is important for cell proliferation. When TRPM8 is deficient in pancreatic cancer, ability of cell proliferation and progression is reduced with elevated levels of cyclin-dependent kinase inhibitors.

Lung cancer: TRPM7 is correlated with EGF expression, known as pro-oncogen. The depletion of TRPM7 in A549 lung cancer cells via siRNA inhibits cell migration. TRPM8 contributes 
an invasive phenotype in lung cancer via synergic action with TRPA1. TRPM2-AS (long non-coding) RNA is widely upregulated in non-small cell lung cancer tissues compared to adjacent non-tumor tissues. Patients with TRPM2 high expression level had poorer survival than with low TRPM2-AS levels. Knockdown of TRPM2AS significantly inhibits cell proliferation. TRPM5 is involved in lung metastasis. It increases the rate of acidic pH induced MMP9 expression. triphenylphosphine oxide (TPPO) an inhibitor of TRPM5 in treatment of tumor bearing mice, significantly reduced spontaneous lung metastasis.

Breast cancer: TRPM7 \& TRPM8 expression level is higher in human breast ductal adenocarcinoma (hBDA) tissue as compared to adjacent non-tumor tissue. Positive correlation between Ki67 mitosis marker and upregulated TRPM7 suggests it's role in breast cancer cell proliferation. It also influences cell adhesion \& migration via regulation of myosin-IIA filament stability \& also influences protein localization by phosphorylating the heavy chain. This migration \& invasion of MDA-MB-435 breast cancer cells is involved in MAPK signaling pathways. Silencing TRPM7 can decrease the level of MAPK. TRPM8 is highly expressed in both the mRNA \& protein levels in MCF-7 breast cancer cell line as well as in breast adenocarcinoma which is correlated with estrogen receptor positive (ER+) tumors. TRPM2 acts as a protector of genomic DNA by minimizing DNA damage in breast cancer cells, thus promotes tumoral growth.

Melanoma: TRPM1 channel was first discovered on the cell line of the B-16 mouse melanoma. It's expression decreases steadily during the progression of primary cutaneous \& vertical growth phase melanomas. The TRPM1 gene is considered a suppressor of tumors. The level of expression is higher in poorly metastatic forms of the melanoma cell line. Decreased TRPM1 expression in production associated with melanoma correlates with the melanoma cell transition from a low to high metastatic phenotype and patient prognosis. TRPM7 Channels serve as defensive devices in both melanocytes physiology \& act as detoxifiers in melanoma cells. TRPM2 acts as a factor that causes melanoma apoptosis \& necrosis. TRPM8 inhibits pigmentation of the melanocytes. It increases the intracellular $\mathrm{Ca}^{+2}$ concentration and amplitude of the current; this reduced the survival of melanoma cells. Therefore, TRPM8 has its role in melanoma proliferation [14].

\section{Conclusion}

TRPM family is activated by multitude of stimuli and plays an important, non-redundant role in variety of physiological condition, that makes them an important target for the treatment of various diseases including neurodegenerative diseases (TRPM2/7), cancer (TRPM8/4), melanoma (TRMPM1). Though much more known about these channels, but complexity of interesting functions, involvement of multiple endogenous modulators in channel activation and close sequence relationship are the opposing condition for the development of potent and specific TRPM modulators.

\section{References}

1. Cohen MR, Moiseenkova-Bell VY (2014) Chapter Seven - Structure of Thermally Activated TRP Channels. Current Topics in Membranes 74: 181-211.

2. Samanta Amrita, Hughes ET Taylor, Moiseenkova-Bell Y Vera (2018) Transient Receptor Potential (TRP) Channels. Subcell Biochem 87: 141165.

3. Thiel G, Rubil S, Lesch A, Guethlein A, Oliver GR (2017) Transient receptor potential TRPM3 channels: pharmacology ,signalling, and biological functions. Pharmacological Research 124: 92-99.

4. Guo J, She J, Zeng W, Chen Q, Bai X, et al. (2018) Structures of the calciumactivated, non-selective cation channel TRPM4. HHS Public Access 552(7684): 205-209.

5. Duan J, Li Z, Li J, Hulse RE, Santa-Cruz A, et al. (2018) Structure of the mammalian TRPM7, a magnesium channel required during embryonic development. 115(35): E8201-E8210.

6. Belrose JC, Jackson MF (2018) TRPM2 : a candidate therapeutic target fortreating neurological diseases. Acta Pharmacol Sin 39(5): 722-732.

7. Yin Y,Wu M, Zubcevic L, Borschel WF, Lander GC, et al. (2018) Structure of the cold- and menthol-sensing ion channel TRPM8. Science 359(6372): 237-241.

8. Jiang L, Li X, Syed SA, Lovatt M, Yang W (2018) The TRPM2 channel nexus from oxidative damage to Alzheimer's pathologies : An emerging novel intervention target for age-related dementia Ageing Research Reviews 47: 67-79.

9. Sun Y, Sukumaran P, Schaar A, Singh BB (2015) TRPM7 and its role in neurodegenerative diseases. Channels (Austin) 9(5): 253-261.

10. Yang CP, Zhang ZH, Zhang LH, Rui HC (2016) Neuroprotective Role of MicroRNA-22 in a 6-Hydroxydopamine-Induced Cell Model of Parkinson's Disease via Regulation of Its Target Gene TRPM7. J Mol Neurosci 60(4): 445-452.

11. Chung Kenny KH, Freestone PS, Lipski J (2011) Expression and functional properties of TRPM2 channels in dopaminergic neurons of the substantianigra of the rat. Journal of Neurophysiology 106(6): 28652875.

12. Gao Y, Liao P (2019) TRPM4 channel and cancer. Cancer Letters 454: 66-69.

13. Nilius B, Owsianik G, Voets T, Peters JA (2007) Transient receptor potential cation channels in disease. In Physiological Reviews 87(1): $165-217$.

14. Ghesquier-Hantute A, Haustrate A, Prevarskaya N, KyiLehen V (2018) TRPM Family Channels in Cancer. Pharmaceuticals 11(2): 58. 
(C) Commons Attribution 4.0 License

To Submit Your Article Click Here: Submit Article

DOI: $10.32474 / 0 J N B D .2020 .04 .000192$

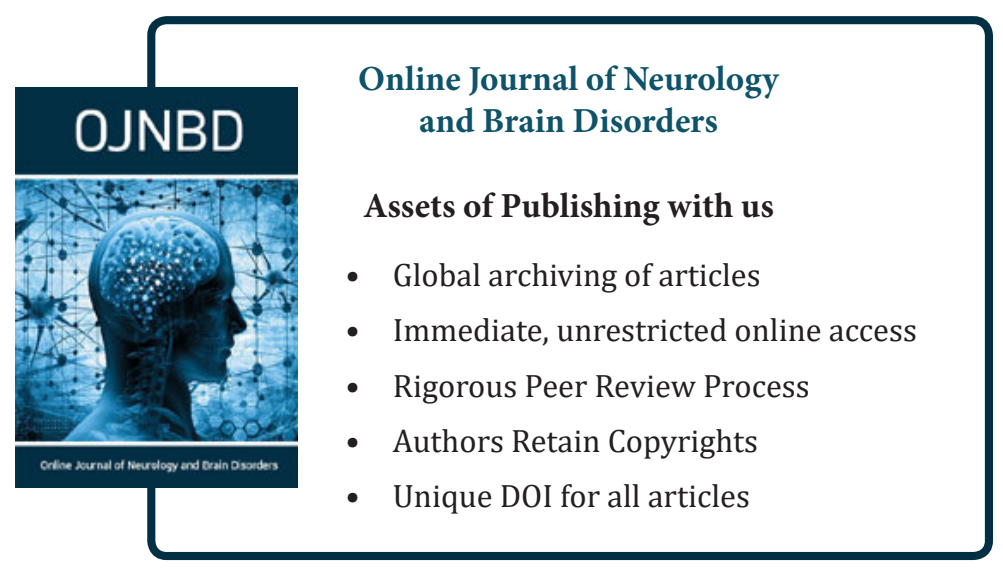

